\title{
OS FORMADORES DE PREFERÊNCIAS EM BLOGS: importância deste ambiente na sobrevivência organizacional
}

\author{
Preference opinion makers in blogs: \\ the importance of this environment for the organizational survival
}

\begin{abstract}
Cíntia Carvalho ${ }^{a}$, Helaine Abreu Rosa ${ }^{\mathrm{b}}$
a Graduada em Comunicação Social - Relações Públicas (PUCRS), Mestre e Doutora em Comunicação Organizacional (PUCRS). Docente de graduação e pós-graduação e pesquisadora do Grupo de Pesquisa em Comunicação e Cultura do Centro Universitário Feevale. Professora convidada de pós-graduação do Instituto Metodista IPA e do IBGEN - Instituto Brasileiro de Gestão e Negócios, Porto Alegre, RS - Brasil, e-mail: ccarvalho@feevale.br / cicarp@terra.com.br

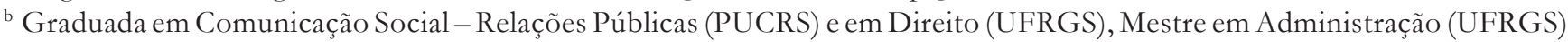
e Doutora em Comunicação Organizacional (PUCRS). Docente de graduação e pós-graduação e pesquisadora do Grupo de Pesquisa em Comunicação e Cultura do Centro Universitário Feevale. Professora convidada de pós-graduação do Instituto Metodista IPA e do IBGEN - Instituto Brasileiro de Gestão e Negócios, Porto Alegre, RS - Brasil, e-mail: helainerosa@feevale.br/ helainer@hotmail.com
\end{abstract}

\begin{abstract}
Resumo
A opinião pública é um fenômeno coletivo que representa uma realidade dos indivíduos e pode ser encontrada de forma ativa na internet, principalmente nos blogs, ambientes esses que influenciam o status quo das organizações. Este ensaio tem o propósito de indicar um conceito de opinião pública e a influência desse processo na rede, pois as corporações não podem ignorar este fenômeno, passível de ser um canal de difamação, consolidação, destruição ou fortalecimento da imagem organizacional.
\end{abstract}

Palavras-chave: Opinião pública; Blogs; Gestores da comunicação; Formadores de preferências.

\begin{abstract}
The public opinion is a collective phenomenon that represents a reality of the individuals and can be found of active form in the InterNet, mainly in blogs, environments these that influence the status quo of the organizations. This essay has the intention to indicate a concept of public opinion and the influence of this process in the net, therefore the corporations cannot ignore this phenomenon, passible of being a defamation canal, consolidation, destruction or fortification of the organizacional image.
\end{abstract}

Keywords: Public opinion; Blogs; Communication managers; Preference opinion makers. 


\section{OPINIÃO PÚBLICA: EM BUSCA DE UM CONCEITO}

A expressão opinião mostra-se ambígua, vaga, indeterminada, uma vez que não há nítida demarcação entre os objetivos, sendo interdisciplinar entre sociologia, psicologia, história, política, estatística. Os estudiosos sobre o assunto questionam-se constantemente quanto ao conceito, ou debruçam-se sobre explicações científicas para o surgimento, fixação e desaparecimento da opinião pública.

Neste caminho, opinião pública é explicada por Da Viá (1983) como um fenômeno coletivo que se apóia numa realidade individual.

A opinião pública é usualmente considerada como resultante de opiniões individuais em torno de determinados assuntos. Não é a média dessas opiniões individuais, pois, na sua formação, atuam fatores fundamentais do comportamento humano e fatores típicos da sociedade, promovendo um processo de interação.

Assim, a opinião pública pode variar segundo fatores emocionais de difícil previsão e avaliação. Dentro de épocas normais, em que não ocorrem quaisquer fatos novos ou perturbadores, é possível obter-se uma previsão bastante aproximada dos resultados, principalmente de pleitos eleitorais. O importante é verificar a existência do fenômeno e as linhas gerais do seu comportamento.

A formação deste fenômeno se dá, em primeiro lugar, a partir de uma fase onde se cria uma consciência coletiva sobre determinada questão ou tema. Começam a surgir manifestações de diversas pessoas, em geral os líderes da comunidade, expressando pontos de vista sobre o assunto. Um grupo passa, então, a agir, destacandose por sua ação de liderança em prol de um determinado ponto de vista. A idéia, ao crescer, gera conflitos, que servem para torná-la ponto de discussão, de forma a irradiá-la ainda mais.

Do entrechoque, aparecem impulsores emocionais, que predominam geralmente sobre os racionais. Quando existem apelos ou sentimentos, estes obtêm com freqüência uma boa resposta, pois o ser humano é emocional por natureza. Assim, a opinião pública é resultante das opiniões dos públicos. Susskind e Field (1997, p. 11) dizem que "o público não expõe suas preocupações diretamente ao responsável [...]", em vez disso, o drama é representado na imprensa ou em quaisquer outro meio de divulgação (por meio dos blogs, por exemplo, face aos novos tipos de relacionamentos instituídos no ambiente virtual) e depois podem gerar um conflito ou crise, podendo parar nos tribunais.

O público pode ficar descontente com todo tipo de acontecimento, pessoal ou coletivo. Diante disso, insatisfeitos, os cidadãos voltamse contra as instituições que as representam ou se filiam a outras, de maneira a aumentar a força de pressão em busca de seus interesses.

O desenvolvimento deste processo está diretamente relacionado com o grau de influência exercido pelos grupos de pressão. Esses, por sua vez, agem de forma ordenada e planificada para tirar proveito de uma situação, ou criam pressão para atingir um objetivo, de maneira racional na utilização dos meios. Henriques, Braga e Mafra (2002) indicam que os públicos são definidos e vinculados a outros públicos por meio de uma série de elementos a partir de interesses comuns, da ação destes, da coesão da continuidade e do senso de co-responsabilidade. Os autores registram que a prática dos públicos é permanente, o que gera um processo continuado de participação e co-responsabilidade. Para Wragg (1989, p. 121), existem duas maneiras de lidar com os grupos de pressão: a primeira "é o de se opor a eles e fazer esforços desmedidos para defender o próprio ponto de vista, ignorando-os quando possível, de forma a obter apoio público ou da mídia; a segunda maneira é o de buscar cooperação".

É possível perceber que a ação dos públicos pode gerar processos de influenciação, impulsionados por interesses variados e objetivos diferenciados. Nessa linha, Simões (2001) apresenta a idéia de que o conceito de público foi substituído pelo de stakeholders - agentes de influência - pelo fato de configurarem posturas e atitudes que podem afetar ou afetam as decisões organizacionais.

Fossati (2006, p. 103) complementa que "o cidadão, o contribuinte, o usuário e o consumidor - considerados como agentes de influência - reivindicam as diversas mediações para influenciar e encaminhar suas demandas [...]" às variadas esferas existentes.

Neste cenário, menos pretensioso talvez, pode-se indicar a existência de recomendações de pessoas comuns - os formadores de 
preferências - que se interessam sobre algum assunto em particular e partilham sua opinião com outros interessados, sendo geradores de uma informação até de mais valor do que a informação veiculada por órgãos oficiais. Os novos formadores de preferência são pessoas cujas opiniões são respeitadas, segundo Anderson (2006), jornalista da Wired, autor da obra $A$ cauda longa: do mercado de massa para o mercado de nicho, e são indivíduos que podem ser encontrados em blogs e grupos diversos (como listas de discussão e redes sociais). Os sistemas de recomendação podem surgir, também, a partir de determinadas ferramentas instaladas em sites de venda de produtos e serviços e por ferramentas que monitoram as preferências.

\section{A OPINIÃo PÚBLICA NA REDE}

Neste contexto, temos que o número estimado de internautas gira em torno de mais de um bilhão de pessoas, cada uma com seu modo particular de viver, com sentimentos, idéias, desejos, frustrações, opiniões e, principalmente, com "vontade de compartilhar todos os itens anteriores com outras pessoas. Essa última não pode ser ignorada quando a própria internet passa a ser o meio de comunicação em que toda essa eletricidade fluirá" (CIPRIANI, 2006, p. 20).

Seguindo a idéia do autor indicado, temos que "essa colaboração em massa se dá por meio de opiniões em lojas de comércio eletrônico e websites diversos, fóruns de debate sobre todo tipo de assunto, salas de bate-papo, colaborações de textos e artigos, e muitos outros meios" (CIPRIANI, 2006, p. 20), como também é o caso dos blogs.

A comunicação em rede representa um rompimento com uma série de conceitos que a comunicação de massa, em seus diversos instrumentos, imprime no fazer social. A internet em especial, pela rapidez com que vem galgando mercados, é o primeiro e talvez referencial marco para essa transformação.

Na internet há uma diversidade de idéias, onde "grupos de pessoas produzem escolhas democráticas [...]" (CIPRIANI, 2006, p. 21). Há a presença de um "potencial democrático" neste ambiente, onde nunca foi tão fácil acessar dados e nunca as informações estiveram disponíveis de forma tão abundante (NEGROPONTE, 1995).

A informação, neste cenário, perde seu caráter de poder. Com a comunicação em rede não existem barreiras para a propagação de dados. Possui o poder aquele que melhor otimizar as informações. Influencia aquele que tem a capacidade de cruzar e checar dados, livrando-se de grande parte da cadeia de mediação proposta pelo veículo de massa. Importante salientar que a mediação não desaparece, mas o espectro de visões da realidade pode ser captado sob distintos ângulos com a internet.

Algumas pessoas argumentam que a Internet e as novas tecnologias de comunicações diminuíram a força repressora da mídia e abriram uma era sem precedentes de democracia interativa. Tanto é verdadeiro quanto importante o fato de a internet aumentar a eficiência e o escopo da formação de redes individuais e de grupos. O que existe é um conjunto, mais ou menos diferenciado, de agentes em luta que procuram impor seu conceito (em geral, de forma interessada) de "opinião pública" (CHAMPAGNE, 1996).

Os blogs são um exemplo de espaço virtual que possibilita a ação em comunidade com outros usuários, com sua interface descomplicada e fácil de implementar, simples de atualizar, de baixo custo e, principalmente, abertos a comentários e opiniões. Cipriani (2006, p. 30) afirma que "no meio da blogosfera existem muitas pessoas de opinião que estão continuamente gerando material interessante". O autor prossegue apontando que "os blogs fazem o papel de catalisador de notícias e fatos relevantes. São um verdadeiro canal de marketing boca-a-boca".

Weblogs ou blogs, na sua versão abreviada, são ferramentas de fácil atualização em web sites em HTML, que se baseiam no sistema de microconteúdos e na atualização quase que diária deles.

De acordo com estatísticas do Technorati, ${ }^{1}$ no começo de Abril de 2007, o número estimado de blogs no mundo atingia a 170 milhões (5,9 milhões são brasileiros). Cada dia é gerado 120.000 novos blogs - 1,4 por segundo em média. Quanto ao número de textos que

\footnotetext{
1 Ver <http://technorati.com>. Acesso em: out. 2007.
} 
diariamente são publicados nos blogs, Technorati estimou uma média diária de 1,5 milhão (17 comentários ou posts por segundo).

No Brasil, de acordo com o Ibope/ NetTatings, ${ }^{2}$ "em Agosto deste ano (2007), aproximadamente nove milhões de usuários acessaram e leram blogs. O número representa $46 \%$ de internautas ativos no mês e reforça o crescimento da blogosfera no país.

De acordo com Pinto (2002), essas páginas da $W e b$ podem ser criadas automaticamente por um sistema predefinido em algum servidor. O mais popular servidor é o Blogger, que foi adquirido pelo Google em 2004. O primeiro passo é criar sua conta no sistema e, a partir da formatação escolhida, basta começar a escrever os textos e selecionar imagens desejadas para a publicação (postagens).

Anderson (2006) apóia-se em dados fornecidos por várias empresas dos Estados Unidos e conta com pesquisadores das universidades de Harvard, Stanford e do MIT para falar de como na economia digital, especialmente aplicada ao mundo do entretenimento (músicas, CDs, DVDs, livro, softwares, etc.) a regra dos 80/20 não se aplica. De acordo com esta regra da economia tradicional, $20 \%$ dos produtos/serviços vendidos por uma empresa respondem por cerca de $80 \%$ das vendas. Robbie Vann-Adibé, CEO da Ecast, espécie de "jukebox digital", citado por Anderson (2006, p. 8), afirmou que essa proporção salta para $98 \%$ no seu negócio de venda de faixas de música digital, afirmando, ainda, que "num mundo em que o custo da embalagem é praticamente zero, com acesso imediato a praticamente qualquer conteúdo nesse formato, os consumidores apresentam um comportamento consistente: olham praticamente tudo". Por outras palavras, enquanto os hits do mercado de massa encontramse em decadência, o mercado de nichos se expande. Não que os hits não existam mais, mas o que se observa é que cada vez se compra mais do que, historicamente, vende menos. E, paralelamente, os hits vendem menos do que em épocas anteriores. $E$ isso graças a: 1) variedade do que se oferece; 2) desigualdade (certas coisas apresentam atributos com mais intensidade do que outras); 3) efeitos de rede, como marketing viral e reputação, que tendem a ampliar as diferenças em qualidade.

A seguir, Anderson (2006, p. 124) justifica o nome de sua teoria:

As leis de potência são uma família de curvas que se encontra praticamente em qualquerobservação, desde fenômenos biológicos até vendas de livros. A Cauda Longa é uma lei de potência, decepada com crueldade pelos gargalos de distribuição, como limitação de espaço nas prateleiras e nos canais disponíveis. Como a amplitude de uma lei de potência se aproxima de zero, mas nunca chega a alcançar esse ponto, à medida que a curva se estende até o infinito, ela é conhecida como curva de "cauda longa", de onde extraí o título deste livro.

Graficamente, obtém-se o seguinte com relação à cauda longa, em que na vertical tem-se a popularidade dos produtos e serviços e, na horizontal, os produtos e serviços em si.

As três forças da cauda longa são: 1) democratização das ferramentas de produção; 2) democratização das ferramentas de distribuição; 3) ligação entre oferta e procura. Os três itens estão estreitamente ligados e referem-se à flexibilidade e ao barateamento de questões logísticas. A terceira força relaciona-se com a conversação entre os consumidores por meio de vários tipos de suportes de comunidades virtuais e com o fato, decorrente disso, de que há muito mais preferências do que sugerem os planos de marketing.

Em parte devido a isso, Wu (2006), professor na Columbia Law School e co-autor de Who controls the internet? Illusions of a Borderless World (2006), critica Anderson (2006), afirmando que as forças da cauda longa não se aplicam a todo o tipo de negócio, mas, principalmente, aos da indústria de entretenimento e de informação. Ou seja, a teoria não se aplicaria em negócios em que a standartização é necessária, em que, conseqüentemente, os consumidores não têm muito o que escolher. Talvez o ponto mais contundente da crítica de Wu (2006) aponta para o aspecto generalista por vezes sugerido no texto de Anderson, de que "a cauda longa está por todos os lados".

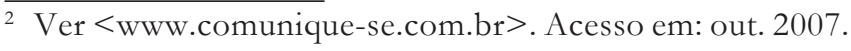


Na medida em que os blogs popularizamse no país, aumentam os riscos de que seus autores utilizem-se dessa ferramenta para beneficiar ou comprometer uma corporação. Frente a isso, a reflexão proposta torna-se pertinente pelo fato de que os blogs fazem-se presente na vida das empresas, estejam elas a par ou não do que se diz sobre elas neste canal. Assim, percebe-se a importância de se usar essa nova forma de comunicação a favor das organizações no sentido de monitorar essas ferramentas e ampliar a possibilidade de diálogo com seus públicos.

A demanda deve-se ao fato de que o ambiente blog vem se consolidando como um local fértil para identificação e monitoramento do que as pessoas dizem e pensam sobre as organizações, seus produtos e/ou serviços. Assim, tem-se que o rastreamento desse espaço específico pode auxiliar numa atuação mais ágil, evitando que um boato, por exemplo, prejudique a imagem de uma empresa ou, ao menos, minimize os impactos causados pela informação lançada. É preciso, nesse sentido, o desenvolvimento de um sistema de software que "garimpe" informações das mais variadas naturezas sobre dados de interesse de determinada organização.

E é exatamente por isso que os blogs merecem atenção: nunca os consumidores puderam se expressar com tamanha liberdade e alcance, o que pode representar oportunidades e ameaças para as empresas, pois sua reclamação ou elogio pode ser facilmente localizado nos mecanismos de busca específicos para blogs por consumidores interessados em determinadas marcas. Juntamente com os blogs, as redes de relacionamento e listas de discussão indicam que as instituições perderam o privilégio da informação, como aponta Ronald Mincheff, presidente da filial brasileira da Empresa de Relações Públicas Edelman. O executivo ainda aponta que as opiniões das pessoas comuns ganham cada vez mais credibilidade do que as veiculadas por um meio de comunicação.

A força dos blogs está em possibilitar que qualquer pessoa, sem nenhum conhecimento técnico, publique suas idéias e opiniões na web e que milhões de outras pessoas publiquem comentários sobre o que foi escrito, criando um grande debate aberto a todos.
As conversas, idéias e opiniões que se dão por meio dos blogs podem facilmente se tornar virais e atingir um enorme número de pessoas em um curto espaço de tempo. São milhões de "blogueiros" opinando sobre notícias, acontecimentos, produtos e serviços, entretenimento, etc. Eles podem estar falando sobre sua empresa, interagindo com seus funcionários, discutindo sobre seus produtos e avaliando seu atendimento, relatando experiências pessoais boas ou ruins, contando suas frustrações ou elogiando sua área de atendimento ao cliente. Essas opiniões certamente atingem a imagem que os leitores formam sobre sua empresa e seus produtos e influencia decisões de compra, no melhor estilo "boca-a-boca" virtual - com força e um alto nível de credibilidade. E este é apenas um aspecto da importância dos blogs e seu impacto no mundo corporativo.

Essas novas tecnologias democratizaram as comunicações, num cenário onde a opinião pública está mais forte e organizada, de forma a exercer grande influência sobre a longevidade das organizações. A internet representa uma nova mediação capaz de mudar as relações dos homens em comunidades públicas ou privadas, virtuais e aponta para um estágio avançado da sociedade, o que pode suscitar uma melhoria na interação entre os públicos e as organizações.

Então, por que não utilizar os blogs como ferramentas de monitoramento sobre hábitos, costumes, preferências e frustrações de seus stakeholders?

O histórico de uma organização e seu comportamento ético, ao longo de sua existência, são fatores importantes para a formação de uma marca ou para o reconhecimento de uma companhia pela opinião pública, especialmente para os formadores de opinião.

Dessa maneira, as organizações socialmente responsáveis têm valores incorporados à marca e aos produtos e/ou serviços por elas oferecidos; conquistam respeito social, clientes fiéis e apresentam melhores resultados financeiros. São unidades que movimentam a economia, oferecem oportunidades, protegem o meio ambiente, preocupam-se com a educação e a qualidade de vida dos cidadãos.

Uma imagem favorável é algo difícil de ser conquistada, sendo ainda mais difícil de manter 
e fácil de perder. Pode-se trabalhar muito tempo na construção de uma imagem e em sua conservação, mas, em poucas horas, pode-se colocar tudo a perder. Fazendo-se uso das imagens de áreas e setores fundamentais da economia, percebe-se que centenas de produtos e serviços estão sendo corroídos em sua identidade e significação, por conta de situações de deterioração geral da qualidade, mas, possivelmente, também pela razão dos seus fabricantes ou dirigentes relaxarem em suas políticas de comunicação (POYARES, 1998).

Por meio dos blogs, as corporações podem obter dados valiosos sobre hábitos, costumes, preferências e frustrações dos seus clientes, rastreando, inclusive, possibilidades de riscos à imagem e reputação organizacional.

Assim, estes canais podem proporcionar uma avaliação prévia das ações de uma empresa, podendo-se ter uma idéia se está agradando, se suas mensagens estão sendo corretamente compreendidas ou perceber algum indício de problemas, o que permite tomar providências a fim de evitar a constituição de crises que abalem a estrutura oragnizacional. É uma ferramenta com alta interatividade e poder de divulgação, da qual as empresas não podem mais ignorar.

A Lei de Sturgeon, autor de ficcção científica, é que "noventa por cento de tudo é desprezível”, informa Anderson (2006). Se isso for considerado, ainda que essa lei também possa ser aplicada no caso da opinião, nada garante que opiniões desprezíveis não prejudiquem a imagem das empresas. É papel dos gestores da informação e da comunicação verificar que tipo de conseqüências a opinião pode ter sobre o seu negócio, seja ela desprezível ou não.

\section{CONSIDERAÇÕES EM CARÁTER DE PROVISORIEDADE}

Até o momento, é possível fazer considerações, tais como:

- a opinião pública é formada a partir de alguma controvérsia de interesse geral, que mereça debate nos espaços democráticos onde as pessoas podem exercitar seu poder de influência sobre a opinião de outros indivíduos na busca de uma união que será diferente da média dos argumentos apresentados; esta, por sua vez, tem a capacidade de mover as instâncias formais de decisão, de maneira a produzir determinada imagem que pode refletir algo positivo ou negativo acerca de alguma organização, alguém, alguma coisa;

- fatores como liberdade para expressar suas opiniões, possibilidade de anonimato, a diversidade de culturas e idéias, a instantaneidade, dentre outros, permitem um aumento exponencial de ligações entre as pessoas/pessoas, pessoas/ organizações e organizações/pessoas;

- os blogs são ferramentas que fazem parte da Web e permitem que o usuário possa ser um emissor neste espaço, por meio das informações que pode publicar a partir delas, em diferentes formatos (som, imagem, texto, fotos, etc.), o que acontece de maneira mais reduzida nos meios de comunicação de massa;

- os blogs surgem como expoentes canais de comunicação e interação nestes contextos, principalmente, por se constituírem em espaços de simples acesso e manuseio, fazem com que seja repensada a dinâmica social vigente a partir desta nova mediação presente;

- as corporações não podem ignorar este fenômeno, já que este pode ser um canal de difamação, consolidação, destruição ou fortalecimento da imagem organizacional.

Com este enfoque e, justamente, com o intuito de auxiliar na criação de fóruns de discussão dos conflitos e crises organizacionais, na interação e intercâmbio de informações relativas a ameaças para as organizações é que os blogs podem ser inseridos, apresentando-se como uma ferramenta interativa para monitorar e encontrar soluções para impasses (possíveis e/ ou já deflagrados).

A força dos blogs está em possibilitar que qualquer pessoa, sem nenhum conhecimento técnico, publique suas idéias e opiniões na web e que milhões de outras pessoas publiquem comentários sobre o que foi escrito, criando um grande debate aberto a todos.

As conversas, idéias e opiniões que se dão por meio dos blogs podem facilmente se tornar virais e atingir um enorme número de pessoas em um curto espaço de tempo. São milhões de "blogueiros" opinando sobre notícias, acontecimentos, produtos e serviços, entretenimento, etc. Eles podem estar falando da empresa, interagindo com os funcionários, discutindo sobre os produtos e avaliando o 
atendimento, relatando experiências pessoais boas ou ruins, contando frustrações ou elogiando a área de atendimento ao cliente. Essas opiniões certamente atingem a imagem que os leitores formam sobre a empresa e seus produtos e influencia decisões de compra, no melhor estilo "boca-a-boca" virtual - com força e um alto nível de credibilidade. E este é apenas um aspecto da importância dos blogs e seu impacto no mundo corporativo.

Todas estas vozes podem ser encaradas como um problema ou como oportunidades. Desde que se esteja atento a elas, não as ignore, porque elas certamente não irão embora de repente. É uma nova realidade que veio para ficar e, com ela, a necessidade das empresas se adaptarem.

O que revela o sentido a este ensaio é exatamente a identificação de que essas novas tecnologias democratizaram as comunicações, num cenário onde a opinião pública está mais forte e organizada, de forma a exercer grande influência sobre a longevidade das organizações. É possível afirmar, sob este enfoque, que é inútil continuar a desconsiderar este canal. A tendência é usar as novas ferramentas a favor da organização, mantendo um canal de comunicação com os funcionários e monitorando periodicamente a imagem e a reputação das empresas, inclusive, grandes companhias já perceberam o poder dos blogs e começaram a usá-los.

\section{REFERÊNCIAS}

ANDERSON, Chris. A cauda longa do mercado de massa para o mercado de nicho. Rio de Janeiro: Campus, 2006.

CHAMPAGNE, Patrick. Formar a opinião: o novo jogo político. Petrópolis: Vozes, 1996.

CIPRIANI, Fábio. Blog corporativo. São Paulo: Novatec, 2006.

DA VIA, Sarah Chucid. Opinião pública: técnicas de formação e problemas de controle. São Paulo: Loyola, 1983.

ESTATÍSTICAS do Technorati. State of blogosphere. Disponível em: <http:// technorati.com>. Acesso em: 20 out. 2007.
FOSSATI, Nelson Costa. Gestão da comunicação na esfera pública municipal. Porto Alegre: Sulina, 2006.

HENRIQUES, Márcio Simeone; BRAGA, Clara Soares; MAFRA, Rennan Lanna Martins. O planejamento da comunicação para a mobilização social: em busca da coresponsabilidade. In: HENRIQUES, Márcio Simeone (Org.). Comunicações estratégicas de mobilização social. Belo Horizonte: Dom Bosco, 2002.

IBOPE/NetTatings. NOVE milhões de usuários leram blogs em agosto. Disponível em: <www.comunique-se.com.br>. Acesso em: 21 out. 2007.

NEGROPONTE, Nicholas. A vida digital. São Paulo: Companhia das Letras, 1995.

PINTO, Marcos José. Blogs! seja um editor na era digital. São Paulo: Érica, 2002.

POYARES, Walter Ramos. Imagem pública: glória para uns e ruína para outros. São Paulo: Globo, 1998.

SIMÕES, Roberto José Porto. Relações públicas e micropolítica. São Paulo: Summus, 2001.

SUSSKIND, Lawrence; FIELD, Patrick. Em crise com a opinião pública: o diálogo como técnica fundamental para solucionar disputas. São Paulo: Futura, 1997.

WRAGG, David. Relações públicas em marketing e vendas: uma abordagem gerencial. São Paulo: McGraw-Hill, 1989.

WU, Tim. The wrong tail: how to turn a powerful idea into a dubious theory of everything. 2006. Disponível em: <http:// www.slate.com/id/2146225>. Acesso em: 11 jan. 2007.

Recebido: 10/12/2007

Received: 12/10/2007

Aprovado: 21/12/2007

Approved: 12/21/2007 